\title{
UTILIZATION PATTERN OF CROP RESIDUES AT FARM LEVEL: EVIDENCE FROM DIVERSIFIED RICE-BASED CROPPING SYSTEMS IN BANGLADESH
}

\author{
M. Akteruzzaman and M. Zaman ${ }^{1}$ \\ Professor in the Department of Agricultural Economics, Bangladesh Agricultural \\ University, Mymensingh-2202, Bangladesh
}

\begin{abstract}
The study aims to examine the utilization of crop residues of 458 farm households covering four districts in Bangladesh. Primary data were collected during October to December 2012 through field survey following purposive sampling. The evidence showed that the average age of the respondents were 40.23 years with an average family size of 4.84 . About $37.12 \%$ respondents had above primary level of education and $81 \%$ respondents were engaged primarily in agriculture. The average farm size was found to be 2.61 acre. The annual household income was found BDT 215,584 of which 75 and 25\% came from agriculture and non-agriculture sources, respectively. The study areas were mostly dominated by rice based cropping systems. Among the crop, rice alone contributed $83.14 \%$ of the total cultivated land followed by vegetables $(41.76 \%)$, pulses (39.08\%) and jute with cropping intensities ranges from 153.16 to $282.12 \%$. The whole retention of boro rice was found higher than aman rice and oilseeds and maize were found higher than all crops. No retention of crop residues was found in case of jute and pulses. It was indicated that the retention rate varied crop to crop as well as location to location. The distance had also another major factor on the retention of crop residues. The households were benefited from retention of crop residues by improving soil health, add soil nutrients, improving soil structure and increasing water conservation to the field. The crop residues were mostly used for animal feed followed by cooking fuel and add organic matter to the field. The used cooking fuel come from their own fuel wood (about $14-53 \%$ ), own crop residues (about 10-25\%) and from cowdung (about $4-22 \%$ ), respectively. The sources of animal feed was found from own crops (about 3$52 \%$ ), own crop residues (about 16-18\%) and from green grass (about 6-24\%), respectively. The constraints to retention crop residues and uses were the lack of proper method of harvesting, transporting them to the house, deficit labor and uneconomic. Finally, the study suggests for conducting training on appropriate methods of harvesting, processing of retention crop residues and improvement of transportation of harvested crop at home properly.
\end{abstract}

Key Words: Conservation agriculture, Cropping system, Crop residue, Resource conserving technologies, Versatile multi crop planter

\footnotetext{
1 Senior Lecturer, Department of Business Administration, ASA University, Shaymoli, Dhaka
} 


\section{INTRODUCTION}

In order to feed the huge population, green revolution has emerged in 1960s and priority was given to produce more food in terms of grain through intensification of land usage. It has created a tremendous pressure on limited land resources. New crop variety was introduced as well as chemical fertilizers, pesticides and irrigation. As a result immediate objectives of more grain production have achieved and grain (rice) production has increased by manifold (Miah et. al., 2010). A lot of HYVs, hybrids have been introduced which require increased amount of chemicals. Soil fertility conservation issue is totally ignored. As a result, soil is rapidly losing its fertility (MOA, 1999). Application of inorganic fertilizer and pesticides without any use of organic fertilizer results lot of problems to the soil. Soil become hard, water holding capacity reduced, soil $\mathrm{pH}$ become imbalance that caused some micro-nutrient deficiency (Islam, 2012). Reduced soil microbial activities result less availability of plant nutrients. As a result, the productivity is decreasing day by day.

Chemical agriculture is mainly dependent on external inputs and production cost is unavoidable. There are mainly two reasons. Firstly increase in the quantity of external inputs. In the beginning of green revolution, farmers used only urea and that was about 50 $\mathrm{kg}$ per acre. However, at present farmers are using 6 types of chemical fertilizers (i.e., Urea, TSP, MP, Gypsum, Zinc and Boron). The amount is also manifold higher than the beginning stage. Secondly, the price of chemical fertilizers and pesticides was also increased rigorously. Cost of irrigation has also the opinion in this paper is totally responsibility of the authors. The authors are grateful to ACIAR-iDE Bangladesh Project, International Development Enterprise-Bangladesh for financial support to conduct the study increased nearly 6 times. The increased use and increased price of agricultural inputs (fertilizer, pesticides, irrigation etc) has made the production cost much higher day by day. Meanwhile, the price of rice has only doubled in last 25 years (Wohab et al., 2009). On the other hand, yield is decreasing. Consequently, farmers getting looser day by day.

However, retention of crop residues under conservation agriculture offers a powerful option for maintain the soil health and increased soil fertility that enhance also soil productivity (Thomas, 2007). The previous studies on utilization of crop residues in Indian sub-continent had bitter experiences. It was found that the utilization pattern of the crop residues was mostly carried at home for cooking as fuel. This is alarming, although the study regarding utilization of crop residue in Bangladesh is very little. Thus, the present study has undertaken to examine the scenario of retention of crop residue status and their utilization pattern in Bangladesh. The broad objective of the study is to examine the utilization pattern of crop residues and their benefits to the farmers in Bangladesh. The specific objectives of this study are as follows:

i. To overview the status on retention of crop residues;

ii. To find out the use of crop residues for different purpose;

iii. To identify the constraints and opportunities to adoption of crop retention and crop residue practices in diversified rice-based cropping systems; and

iv. To suggest some policy guidelines. 


\section{METHODOLOGY OF THE STUDY}

The study covered a range of soils and cropping systems for the evaluation of conservation agriculture: Rajshahi; Mymensingh; Rajbari, and Thakurgoan. Data and information were gathered through focus group discussion (FGD), household survey, and case studies. Focus group were consisted of different sections of people such as Subassistant Agricultural Officer, 2 wheel power tiller, machinery and spare parts sellers, owners, operators, and few conscious local community people. On the other hand, quantitative and qualitative data and information were gathered from the selected users and service providers of machineries for conducting household survey using pre-tested questionnaire. Some suitable case studies of successful service providers were also conducted to supplement the study. The purposive sampling technique was adopted in this study.

For collecting the necessary data, the study team explained respondents the aims and objectives of the study before going for actual interview. The respondents were assured that the information given by them would not be used against their interest. Interviewees were requested to give correct information as far as possible. To ensure the quality of information, the questionnaire was checked to ensure that information to each of the items had been correctly recorded. If there were any items overlooked and misunderstood or contradictory, these were corrected through re-interviewing on the spot.

Table 1. Distribution of the selected sample households in the study locations

\begin{tabular}{lc}
\hline \multicolumn{1}{c|}{ Major cropping systems } & No. of selected households \\
\hline $\begin{array}{l}\text { Rajshahi } \\
\text { Rice-lentil-mung bean }\end{array}$ & 120 \\
Rice-wheat-mung bean & $\mathbf{1 2 0}$ \\
\hline $\begin{array}{l}\text { Sub-total } \\
\text { Mymensingh }\end{array}$ & 118 \\
$\begin{array}{l}\text { Rice-mustard-mung bean } \\
\text { Rice- wheat-mung bean } \\
\text { Rice-lentil-Aus rice }\end{array}$ & \\
\hline $\begin{array}{l}\text { Sub-total } \\
\text { Rajbari } \\
\text { Rice-lentil-mung bean }\end{array}$ & $\mathbf{1 1 8}$ \\
Rice-lentil-jute & 160 \\
\hline Sub-total & $\mathbf{1 6 0}$ \\
Thakurgaon & \\
Rice-wheat-mung bean & 60 \\
\hline Sub-total & $\mathbf{6 0}$ \\
\hline Total & $\mathbf{4 5 8}$ \\
\hline
\end{tabular}

Source: Field Survey, 2012 
All the collected data were processed and analyzed in accordance with the objectives of the study. Data processing included field and office editing, coding and tabulation. The data entry template was designed in Microsoft Excel. Consistency checks and keystroke errors were also detected and corrected accordingly before data analysis. The analysis was done using descriptive statistics like percentage, frequency distribution, mean, and rank as necessary.

\section{RESULTS AND DISCUSSION}

\section{Socioeconomic profile of the respondent households}

Socioeconomic information about respondents in study areas are discussed in Table 2. It indicates that the average age of the respondents were 40.23 years. The age variation was similar in all the four study sites where the older age farmers were found in Thakurgaon.

Table 2. Socioeconomic profile of the respondent households

\begin{tabular}{l|c|c}
\hline \multicolumn{1}{c|}{ Socioeconomic parameters } & Unit & All areas \\
\hline Age of the respondents & Years & 40.23 \\
Average family size & No. & 4.84 \\
Literacy above primary level & $\%$ & 37.12 \\
Primarily occupied in agriculture & $\%$ & 81.00 \\
Farm land & Acre & 2.61 \\
Annual income & Taka & $215,583.49$ \\
\hline
\end{tabular}

Source: Field Survey, 2012

Average family size was 4.84 and about $37.12 \%$ respondents had above primary level of education. Mostly ( $81 \%)$ respondents were engaged primarily in agriculture. The average land area of the respondents was 2.61 acres. The annual household income was found BDT 215,584 of which $75 \%$ and $25 \%$ came from agriculture and non-agriculture sources, respectively.

\section{Cropping system practiced}

Table 3 shows the total land cultivated by different crops in study areas. In study areas, the main crops were rice, wheat, jute, pulses, oilseed, maize and vegetables. Rice was the main cultivated crop and vegetables were the second one. The total cultivated area by rice, wheat, jute, pulses, oilseed, maize and vegetables were 2.17, 0.43, 0.74, 1.02, 0.46, 0.66 and 1.09 acres respectively where the percentage of total cultivated land of the above crops were $83.14,16.48,28.35,39.08,17.62,25.29$ and 41.76 , respectively.

The cropping pattern and intensity in study areas are represented in Table 4. For the first cropping pattern in Rajbari, Boro rice grows in Rabi season, Jute in Kharif I and Aman in Kharif II and $22 \%$ respondents cultivated this pattern. The cropping intensity was found $196.43 \%$. In Rajshahi, Boro rice grows in the first cropping pattern in Rabi season, Jute in 
Kharif I and Aman in Kharif II, where 12\% respondents cultivated in this pattern with cropping pattern $282.12 \%$. In Thakurgaon, $48 \%$ respondents followed Boro-Fallow-Aman cropping pattern and the cropping intensity was 223.33\%. In case of Mymensingh, 35\% respondents followed Boro-Jute-Aman cropping pattern and the cropping intensity was $153.16 \%$.

Table 3. Crops cultivated by the sample households

\begin{tabular}{lccc}
\hline \multicolumn{1}{c|}{ Crops } & Area (in acres) & \% of total \\
\hline Rice & 2.17 & 83.14 \\
Wheat & 0.43 & 16.48 \\
Jute & 0.74 & 28.35 \\
Pulses & 1.02 & 39.08 \\
Oilseeds & 0.46 & 17.62 \\
Maize & 0.66 & 25.29 \\
Vegetables & 1.09 & 41.76 \\
\hline
\end{tabular}

Source: Field Survey, 2012

Table 4. Major cropping patterns and cropping intensity of the sample households

\begin{tabular}{l|c|l|c|c|c|c}
\hline \multicolumn{1}{c}{ Location } & Pattern & \multicolumn{1}{c}{ Rabi } & Kharif I & Kharif II & $\begin{array}{c}\% \text { of } \\
\text { households }\end{array}$ & $\begin{array}{c}\text { Cropping } \\
\text { intensity (\%) }\end{array}$ \\
\hline Rajbari & 1 & Boro rice & Jute & Aman & 22 & 196.43 \\
& 2 & Oilseed/ Pulses & Aus & Fallow & 33 & \\
Rajshahi & 3 & Wheat & Jute & Fallow & 45 & \\
& 1 & Boro & Jute & Aman & 12 & 282.12 \\
& 2 & Wheat & Fallow & Aman & 57 & \\
Thakurgaon & 3 & Vegetables/Pulse & Aus & Fallow & 31 & \\
& 1 & Boro rice & Fallow & Aman & 48 & 223.33 \\
& 2 & Wheat & Fallow & Aman & 28 & \\
Mymensingh & 3 & Vegetables/Pulse & Aus & Fallow & 24 & \\
& 1 & Boro & Jute & Aman & 35 & 153.16 \\
& 2 & Wheat/Boro & Fallow & Aman & 27 & \\
& 3 & Vegetables/Pulse & Fallow & Aman & 38 & \\
\hline
\end{tabular}

Source: Field Survey, 2012

\section{Status of retention crop residues}

Table 5 represents the pattern of retention crop residue by locations. Here, the retention of crops was divided into three groups: wholly retention, partially retention and no retention. The main crops were boro rice, aman rice, wheat, jute, pulses, oilseeds and 
maize. In Rajbari, $72.28 \%$ respondents used wholly retention method in Boro rice and $73.68 \%$ in oilseed; and $70.30 \%$ used partial method of retention in wheat. No retention method was used by $100 \%$ respondent in maize cultivation. In Rajshahi, $66.67 \%$ respondents used whole method of retention in Maize cultivation while $86.36 \%$ respondents used partial retention method in boro rice cultivation. No retention method used by $100 \%$ respondents in jute cultivation. In Thakurgaon, $38 \%$ respondents used wholly retention method in boro rice and $61.90 \%$ in maize cultivation, respectively. Partial method of retention in wheat was observed by $47.62 \%$ respondent in wheat cultivation. No retention method used by $100 \%$ respondents in Aman rice cultivation.

In Mymensingh, whole retention method was used by $88.89 \%$ respondents in aman rice cultivation while about $90 \%$ respondents used partial method of retention in boro rice cultivation. No retention method used by $100 \%$ respondent in pulses production.

Table 5. Pattern of retention crop residue by locations (\% of households)

\begin{tabular}{l|ccc|c|c|c|c|c|c|c|c|c|c}
\hline \multirow{2}{*}{ Crops } & \multicolumn{3}{|c|}{ Rajbari } & \multicolumn{3}{c|}{ Rajshahi } & \multicolumn{3}{c|}{ Thakurgaon } & \multicolumn{3}{c}{ Mymensingh } \\
\cline { 2 - 14 } & Whole & Partial & No & Whole & Partial & No & Whole & Partial & No & Whole & Partial & No \\
\hline Boro rice & 72.28 & 18.81 & 8.91 & - & 86.36 & 13.64 & 38.00 & 22.00 & 40.00 & - & 89.58 & 10.42 \\
Aman rice & 31.09 & 62.18 & 6.72 & 1.61 & 46.77 & 51.61 & - & - & 100.00 & 88.89 & 8.89 & 2.22 \\
Wheat & 1.98 & 70.30 & 27.72 & - & 35.14 & 64.86 & 9.52 & 47.62 & 42.86 & 8.33 & 91.67 & - \\
Jute & - & 3.16 & 96.84 & - & - & 100.00 & 4.55 & 22.73 & 72.73 & - & - & - \\
Pulses & - & 7.04 & 92.96 & 3.33 & 6.67 & 90.00 & 14.29 & - & 85.71 & - & - & 100.00 \\
Oilseeds & 73.68 & 7.89 & 18.42 & 7.14 & 7.14 & 85.71 & - & - & - & - & - & - \\
Maize & - & - & 100.00 & 66.67 & - & 33.33 & 61.90 & 23.81 & 14.29 & - & - & - \\
\hline
\end{tabular}

Source: Field Survey, 2012

In case of pattern of retention crop residue in all household, Table 6 represents the cropwise classification of whole, partial and no use of retention. For boro rice, $41.63 \%$ respondent used both the wholly and partial retention method while $16.74 \%$ didn't use any retention method. About $56 \%$ respondents used whole retention method, $7.69 \%$ respondents used partial retention method and $36.54 \%$ respondents didn't use any retention method in oilseed cultivation. For maize, $57.58 \%, 15.15 \%$ and $27.27 \%$ respondent used whole, partial and no retention method respectively.

Pattern of retention crop residue by distance of plot is shown in Table 7. Cropping lands in study areas were classified into three groups: i) no distance to households ii) little far distance to households and iii) far distance to households. The methods used in crop retention were whole, partial and no retention. In case of no distance to households, whole retention method was used $28.91 \%, 27.74 \%, 1.84 \%, 2.04 \%, 52.27 \%$ and $43.75 \%$ for boro, aman, wheat, pulses, oilseed and maize respectively. Partial retention method was used by $59.38 \%$ for boro rice. About $90-95 \%$ respondents didn't use any retention method for jute and pulses cultivation. In case of little far distance to households, whole retention 
method was used by $55.77 \%$ respondents for oilseed cultivation. For far distance to households, $88.79 \%$ respondents didn't use any retention method for jute cultivation.

Table 6. Pattern of retention crop residue by studied households

\begin{tabular}{l|c|c|c}
\hline \multirow{2}{*}{ Crops } & \multicolumn{3}{c}{ \% of households } \\
\cline { 2 - 4 } & Whole & Partial & No \\
\hline Boro rice & 41.63 & 41.63 & 16.74 \\
Aman rice & 34.21 & 46.93 & 34.86 \\
Wheat & 3.92 & 61.76 & 93.08 \\
Jute & 0.77 & 6.15 & 91.89 \\
Pulses & 1.80 & 6.31 & 36.54 \\
Oilseeds & 55.77 & 7.69 & 27.27 \\
Maize & 57.58 & 15.15 &
\end{tabular}

Source: Field Survey, 2012

Table 7. Pattern of retention crop residue by distance of plot to the households (in per cent)

\begin{tabular}{l|c|c|c|c|c|c|c|cc}
\hline \multirow{2}{*}{ Crops } & \multicolumn{3}{|c|}{ No distance to households } & \multicolumn{3}{c|}{$\begin{array}{c}\text { Little far distance } \\
\text { households }\end{array}$} & \multicolumn{3}{c}{ Far distance to households } \\
& Whole & Partial & No & Whole & Partial & No & Whole & Partial & No \\
\hline Boro rice & 28.91 & 59.38 & 11.72 & 34.21 & 46.93 & 18.86 & 46.91 & 41.98 & 11.11 \\
Aman rice & 27.74 & 48.54 & 23.72 & 32.39 & 32.39 & 13.03 & 36.21 & 53.45 & 10.34 \\
Wheat & 1.84 & 69.59 & 28.57 & 3.92 & 61.76 & 34.31 & 13.77 & 59.88 & 26.35 \\
Jute & - & 6.72 & 93.28 & 0.77 & 6.15 & 93.08 & 5.61 & 5.61 & 88.79 \\
Pulses & 2.04 & 7.14 & 90.82 & 1.80 & 6.31 & 91.89 & 6.38 & 5.32 & 88.30 \\
Oilseeds & 52.27 & 18.18 & 29.55 & 55.77 & 7.69 & 36.54 & 72.09 & 6.98 & 20.93 \\
Maize & 43.75 & 37.50 & 18.75 & 57.58 & 15.15 & 27.27 & 61.11 & 5.56 & 33.33 \\
\hline
\end{tabular}

Source: Field Survey, 2012

Table 8 represents the benefits of retention crop residue in the study areas. The respondent were benefited by improve soil health, add soil nutrients, add organic matter, soil structure, beneficial microbial factor, increase soil worm, increase water conservation, less use of fertilizer and improve farm environment. For all the study locations, $97.16 \%$, $92.63 \%, 47.60 \%, 74.02 \%, 44.10 \%, 39.52 \%, 41.92 \%, 67.03 \%, 62.23 \%$ and $44.10 \%$ respondents were benefited by improve soil health, add soil nutrients, add organic matter, soil structure, beneficial microbial factor, increase agaricus mushroom, increase soil worm, increase water conservation, less use of fertilizer and improve farm environment respectively. It indicates that all the households had knowledge on the benefit of the retention of crop in the land. 
Table 8. Benefits of retention crop residue in the study areas (in per cent)

\begin{tabular}{l|c|c|c|c|c}
\hline \multicolumn{1}{c|}{ Benefits } & Mymensingh & Rajbari & Rajshahi & Thakurgaon & $\begin{array}{c}\text { All studied } \\
\text { areas }\end{array}$ \\
\hline Improve soil health & 93.22 & 98.75 & 95.00 & 100.00 & 97.16 \\
Add soil nutrients & 94.07 & 85.63 & 93.33 & 100.00 & 92.36 \\
Add organic matter & 30.51 & 26.88 & 91.67 & 45.00 & 47.60 \\
Soil structure & 63.56 & 62.50 & 91.67 & 88.33 & 74.02 \\
Beneficial microbial factor & 28.81 & 13.13 & 95.00 & 51.67 & 44.10 \\
Increase agaricus mushroom & 31.36 & 10.63 & 75.83 & 60.00 & 39.52 \\
Increase soil worm & 31.36 & 10.00 & 90.00 & 51.67 & 41.92 \\
Increase water conservation & 62.71 & 44.38 & 94.17 & 76.67 & 67.03 \\
Less use of fertilizer & 61.02 & 41.25 & 94.17 & 51.67 & 62.23 \\
Improve farm environment & 61.86 & 5.00 & 94.17 & 13.33 & 44.10 \\
\hline
\end{tabular}

Source: Field Survey, 2012

\section{Utilization of crop residues}

The uses of the crop residues are presented in Table 9. Farmers in Bangladesh mostly used crop residues either for cooking fuel or animal feed. In addition, cop residues were also used as organic fertilizer. Table 10 represents the extent of using crop residue as cooking fuel in the study areas by the category of households. The sources of cooking fuels are own fuel wood, others fuel wood, purchased fuel wood, own crop residues, others crop residues, own cow dung and others cow dung. It reveals that the highest number of households $(67.97 \%)$ utilized their crop residues as animal feed followed by cooking fuel $(60.26 \%)$ and organic fertilizer $(57.95 \%)$, respectively.

Table 9. Utilization of crop residues in the study areas

\begin{tabular}{l|c|c}
\hline \multicolumn{1}{c}{ Uses } & \% of total households $(\mathrm{N}=458)$ & Rank in order \\
\hline Cooking fuel & 60.26 & 2 \\
Animal feed & 67.97 & 1 \\
Organic fertilizer & 57.95 & 3 \\
Use with cow dung boll & 1.58 & 7 \\
Fired at field & 3.53 & 6 \\
Cut during harvest & 13.96 & 5 \\
Reuse during next cultivation & 27.09 & 4 \\
\hline
\end{tabular}

Source: Field Survey, 2012

The availability of crop residues as animal feed in the study areas are described in Table 10. The sources of animal feed are own crop, others crop, purchased feed, own crop residues, others crop residues and available grass. The status of the amount of crop 
residues that were used for animal feed was divided into three categories, viz. whole, partial and low. The main sources were found from their own fuel wood (about 14-53\%) followed by own crop residues (about 10-25\%) and own cow dung (about 4-22\%). There were less amount of others fuel wood and crop residues used for cooking fuel in the studied households.

The use of crop residue as animal feed in the study areas by category of households is presented in Table 11. The sources of animal feed are own crop, others crop, purchased feed, own crop residues, others crop residues and available grass. The status of the amount of crop residues that were used for animal feed was divided into three categories, i.e., whole, partial and low. It is clear from the table that the whole amount of $51.41 \%$, $0.17 \%, 6.49 \%, 16.97 \%, 1.50 \%$ and $21.76 \%$ of animal feed comes from own crop, others crop, purchased feed, own crop residues, others crop residues and available grass, respectively. The partially used amount of own crop, others crop, purchased feed, own crop residues, others crop residues and available grass as animal feed are $30 \%, 8.82 \%, 15.88 \%, 17.65 \%$, $5.88 \%$ and $21.76 \%$, respectively.

Table 10. Extent of using crop residue as cooking fuel

\begin{tabular}{l|c|c|c}
\hline \multirow{2}{*}{ Crops } & \multicolumn{3}{c}{ All households (\%) } \\
\cline { 2 - 4 } & Whole & Partial & Low \\
\hline Own fuel wood & 52.44 & 13.87 & 26.92 \\
Others fuel wood & 0.65 & 10.95 & 7.69 \\
Purchase fuel wood & 0.16 & 9.49 & 42.31 \\
Own crop residues & 20.29 & 24.82 & 9.62 \\
Others crop residues & 2.27 & 10.58 & 3.85 \\
Own cow dung & 20.13 & 21.17 & 3.85 \\
Others cow dung & 4.06 & 9.12 & 5.77 \\
\hline
\end{tabular}

Sources: Field Survey, 2012

Table 11. Extent of using crop residue as animal feed

\begin{tabular}{l|c|c|c}
\hline \multirow{2}{*}{ Sources } & \multicolumn{3}{c}{ All households (\%) } \\
\cline { 2 - 4 } & Whole & Partial & Low \\
\hline Own crop & 51.41 & 30.00 & 2.94 \\
Other crops & 0.17 & 8.82 & - \\
Purchased & 6.49 & 15.88 & 72.55 \\
Own crop residues & 16.97 & 17.65 & 17.65 \\
Other crop residues & 1.50 & 5.88 & 0.98 \\
Available grass & 23.46 & 21.76 & 5.88 \\
\hline
\end{tabular}

Source: Field Survey, 2012 


\section{Constraints and opportunities of crop residues retention}

The constraints to crop residue retention and their uses by locations are described in Table 12. The study identified the constraints faced by the farmers which were harvesting, carrying, labour deficit, economic loss, difficulties in use, difficulties faced in land preparation and attack of disease and pest infestation. Further, the problem has been given a rank of 1-7. Rank 1 is for the problem that are seemed to be the most serious and rank 7 is for the problem that seemed by the farmers as not so serious. The problem also can be grouped into high, medium and low. In case of all households, $22.22 \%, 21.48 \%$ and $18.82 \%$ claimed that problem faced in carrying, harvesting and the problem of insect and pest infestation were the high, medium and low level of constraints that were faced by the highest number of households in all the study area. Overall it can concluded that carrying problem was the most serious problem in the study areas that deserve the highest rank 1 while rank 7 was land preparation problem that were faced by the responding households in the study areas.

Table 12. Constraints to crop residue retention and their uses by the sample households

\begin{tabular}{l|c|c|c|c}
\hline \multirow{2}{*}{ Constraints } & \multicolumn{3}{c|}{ All households (\%) } & \multirow{2}{*}{ Ranks } \\
\cline { 2 - 4 } & High & Medium & Low & \\
\hline Harvesting & 12.04 & 21.48 & 9.12 & 5 \\
Carrying & 22.22 & 20.05 & 12.94 & 1 \\
Labor deficit & 18.52 & 18.02 & 14.41 & 3 \\
Economic loss & 21.30 & 8.23 & 18.38 & 2 \\
Difficulties in use & 6.17 & 12.65 & 12.50 & 6 \\
Land preparation & 5.86 & 11.93 & 13.82 & 7 \\
Insect and pest infestation & 13.89 & 7.64 & 18.82 & 4 \\
\hline
\end{tabular}

Source: Field Survey, 2012

Opportunities to crop residue retention and their uses are presented in Table 13. Here, the opportunities were ranked into 1-5, 1 is for the highest rank and 5 is for the lowest rank. The item that field should be processed accordingly attained the lowest rank which occupy $6.73 \%$ of the total among the 73 households. The highest rank 1 was given for the item that is, training should be provided at the farm level which occupies $29.81 \%$ of the total among the 73 households. Rank 2, 3 and 4 were given to the items that suitable methods should be developed for each crop, labourer should be trained up accordingly and residues should be cut at a little bit longer which occupies $14.42 \%, 11.54 \%$ and $7.69 \%$ among the 73 households. 
Table 13. Opportunities to crop residue retention and their uses

\begin{tabular}{l|c|c|c}
\hline \multicolumn{1}{c|}{ Items } & No. of households & \% of total & Ranked \\
\hline Training should be provided to the farm level & 31 & 29.81 & 1 \\
Suitable methods should be developed for each crop & 15 & 14.42 & 2 \\
Field should be processing accordingly & 7 & 6.73 & 5 \\
Labourer should be trained up accordingly & 12 & 11.54 & 3 \\
Should be cut little bit longer & 8 & 7.69 & 4 \\
\hline
\end{tabular}

Source: Field Survey, 2012

\section{CONCLUSIONS AND RECOMMENDATIONS}

Based on the empirical findings through field survey, FGD, personal interviewing and key informants' interviewing, the following conclusions and recommendations are made:

> Farmers aged between 31-50 years should be highly encouraged to undertake far, activities with CA technologies because they can perform all activities well than other farmers;

> Farmers should be encouraged to attend training on conservation agriculture techniques so that they can understand the farming system and the benefits of conservation agriculture technologies very well;

$>$ Since agriculture is the main source of income for the respondent households so that they should be encouraged to use conservation agriculture technologies which will facilitate their farming operation at low cost;

$>$ Promotion of knowledge on the benefits of retention of crop residues should be ensured through extension agents, DAE and local NGOs;

> Farmers should be encouraged to utilize their crop residues either for selling, feeding, fuelling and reuse purposes or they can use it as organic fertilizer in the field which will increase the fertility of soil;

$>$ Households in the new conservation agriculture research sites should be encouraged to utilize their crop residues efficiently in order to capture the benefits of conservation agriculture technologies;

$>$ Households should be informed about the various benefits of utilization of crop residues by extention agents or other government and non-government bodies so that they can make best use of conservation agriculture technologies;

$>$ Households should be provided with adequate information and training in all rural areas of Bangladesh through various institutions and extension agents;

$>$ Adequate number of machine should be provided to the farmers at reasonable cost by the responding companies so that the farmers can use them to reduce their time and damage of crop and residues waste in all areas of Bangladesh; 
Promotion of knowledge regarding how to minimise these constraints in case of retention of crop residues should be provided by the extension agents in the study areas; and

All the opportunities to the retention of crop residues should be ensured so that the farmers can best use of these opportunities in all rural areas of Bangladesh.

\section{REFERENCES}

Islam A. K. M. S., Haque, M. E., Hossain, M. M., Saleque, M. A., and Bell, R. W. 2011. Evaluation of versatile multi-crop planter to establish the sprouted direct seeded rice. $5^{\text {th }}$ World Congress of Conservation Agriculture incorporating 3rd Farming Systems Design Conference, 26-30

Miah Monayem M. A., Haque, M. E., Baksh, M. E. and Hossain, M. I. 2010. Economic analysis of power tiller operated seeder operation at farm level. Journal of Agricultural Engineering. (Bangladesh) 38/AE. (1): 19-24.

MoA. 1999. National Agriculture Policy. Ministry of Agriculture. Government of the Peoples Republic of Bangladesh. April 1999.

Thomas G. A., Titmarsh, G. W., Freebairn, D. M. and Radford, B. J. 2007. No-tillage and conservation farming practices in grain growing areas of Queensland - a review of 40 years of development. Australian J. Exp. Agric. 47, 887-898.

Wohab M. A., Ziauddin, Haque, A. T. M., Sayre, M. E., Hossain, K. D. and Hossain, M. I. 2009. Development of single pass bed planter for small holder farming, crop diversification and resource conservation. Proc. Int. Conf. 4th World Congress of Conservation Agriculture. New Delhi, India, p. 302. M/S Print Process, New Delhi, India. 